\title{
Infant Mortality Juvenile and Inequality Income in Niger: Evidence for Regional Differences through Two Case Studies
}

\section{Amadou Ousmane}

Department of Economics and Law, Abdou Moumouni University, Niger, Nigeria

*Corresponding author: Amadou Ousmane, Department of Economics and Law, Abdou Moumouni University, Niger, BP-12442, Niamey, Nigeria, Tel: +22796870087; E-mail: ousmadou70@yahoo.fr

Rec date: April 12, 2017; Acc date: September 27, 2017; Pub date: September 29, 2017

Copyright: () 2017 Amadou O. This is an open-access article distributed under the terms of the Creative Commons Attribution License, which permits unrestricted use distribution, and reproduction in any medium, provided the original author and source are credited.

\begin{abstract}
In this study, we sought to highlight a side of the interrelations between income inequality and health indicators, and other assess the problem taking into account the socio-professional status and regional inequalities. In support databases of EDSN 1998 and EDSN-MICS 2006; after calculating the indicators of inequality, it appears in a preliminary analysis that income inequality has increased in Niger from 1998 to 2006. The analysis of these indicators by region confirms and reinforces the existence of a regional disparity in income inequality. Finally, the level of income inequality by region is itself a determinant of child mortality in Niger. Thus, regions with low child mortality also have the lowest rates of poverty in Niger.
\end{abstract}

Keywords: Infant mortality; Quality; Inequality; Regional income disparity; Population growth

\section{Introduction}

In Niger, health and poverty remain top priorities to all governments that led the country over decades. Unfortunately, these efforts still do not improve much the country's image in the world ranking of development indicators. Regarding health indicators, Niger will still have to face major challenges. Today, life expectancy does go beyond 52 years and a child out of four children does not celebrate the fifth year [1]. This situation is exacerbated by very high population growth making it very difficult providing for coverage of basic services. In this context, a Health Development Plan (PDS) (2005-2010) was designed, with the aim of contributing to the reduction of maternal and child mortality, thus improving the efficiency and quality of care. As far as maternal health is concerned, the rate of delivery in health facilities is still very low $(17.2 \%$ in 2006$)$ with very significant variations according to dwellings and regions ( $8 \%$ of births in rural areas are done in health facilities against $69.5 \%$ in urban areas. The results of the Demographic and Health Survey and Multiple Indicator (EDSN-MICS) 20062 in Niger, revealed that even though infant mortality is drastically reducing, the percentage remains still high: 81 deaths out of 1,000 births. The same applies to the child mortality where we have 198 deaths out of 1,000 births (against 274 out of 1,000 in 1998). However, there is a big discrepancy across the eight regions and between urban and rural areas. Besides the problems of child mortality in Niger, there are those related to the poverty of breadwinners in general and inequality of income. This is both at the level the dwellings as well as particularly that of the eight regions of the country. Although the prevalence of poverty remains essentially constant and marked by profound inequality in regional, socio professional category and area of residence.
In this paper, the research questions will be informed by the relationship between infant mortality and income of the heads of families in Niger. This will be carried out also through the work of Wilkinson [2] and Kawachi [3], which unveils how income inequality has a direct effect on individual health, thus, on infant mortality in every home. The aim here is therefore to determine whether there is a relationship between infant and child morality in Niger and inequality of income amongst breadwinners? Will specifically, examine whether a relationship exists between:

- The mortality of children under five and the socio-professional category of head of families.

- The mortality of children under five and the level of welfare of each household.

- The child mortality and belonging to a specific region.

- In the first section of this work, we present the situation of poverty and health in Niger. In the second, we present a literature review; the third section is devoted to methodology used to carry out this analysis. The main results are presented in the fourth section before ending with the conclusion.

\section{State of Poverty in Niger}

Niger is one of the poorest countries in the world ${ }^{1}$. Therefore, in view of the Human Development Index (HDI), which combines income levels, education and health of the population, it occupies an unenviable position. The table below summarizes the evolution and status of poverty in Niger from 2005 to 2007/2008 (Table 1). However, poverty remains massive primarily because of moderate economic growth achieved during 2002-2005. Niger embarked on a second Poverty Reduction Strategy (PRS) in this context, which ranged from 2008 to 2012. This was commonly known as Accelerated Development Strategy and Poverty Reduction. Other social indicators should also be improved, including access to drinkable water that is expected to

Unlike in 1998 when the survey was called EDSN - 1998 in 2006 because of its combination with the multiple indicator survey; it was then EDSN - MICS. 
Citation: Ousmane A (2017) Infant Mortality Juvenile and Inequality Income in Niger: Evidence for Regional Differences through Two Case

Page 2 of 7

benefit $80 \%$ of the population, infant mortality to 108 infants out of thousand, and literacy rate: $28.7 \%$ for the mainstream population, $45 \%$ of the adult population and the gross enrollment rate would be $94 \%$. The monetary poverty assessment through the National Budget Survey Consumption (ENBC 2007/2008) and the Unique Questionnaire for the Basic Needs of indicators (QUIBB 2005) show that the prevalence of the population living below the threshold of poverty was $62.1 \%$ in 2005 and $59.5 \%$ in 2008 .

\section{Health in Niger}

In Niger, the high levels of child mortality are consistent with the high levels of maternal mortality and fertility. In other words, the reproductive health is characterized by a vicious circle where the interrelations between high levels of fertility, high maternal mortality, and high child mortality maintain sanitary conditions of the majority of families in Niger in a precarious situation.

\begin{tabular}{|c|c|c|c|c|c|c|}
\hline \multirow[b]{2}{*}{ Regions } & \multicolumn{3}{|l|}{2005} & \multicolumn{3}{|c|}{$2007 / 2008$} \\
\hline & Impact & Depth & Seriousness & Impact & Depth & Seriousness \\
\hline Agadez & 45,9 & 16,1 & 8,1 & 16,1 & 4,5 & 1,9 \\
\hline Diffa & 18,8 & 5,3 & 2,2 & 18,3 & 3,5 & 1 \\
\hline Dosso & 67,3 & 28,8 & 15,3 & 66,9 & 24,2 & 11 \\
\hline Maradi & 79,7 & 35,1 & 19 & 73,4 & 26,1 & 12 \\
\hline Tahoua & 45,9 & 14,5 & 6,2 & 57,6 & 18,8 & 7,7 \\
\hline Tilllabery & 68,9 & 26,8 & 13,9 & 71,7 & 23 & 9,5 \\
\hline Zinder & 71 & 26,2 & 12,9 & 53,8 & 15,4 & 6 \\
\hline Niamey & 27,1 & 7,2 & 2,8 & 27,8 & 8,5 & 3,9 \\
\hline Niger & 62,1 & 24,1 & 12,3 & 59,5 & 19,6 & 8,4 \\
\hline
\end{tabular}

Table 1: Evolution of poverty over time and space in Niger.

\begin{tabular}{|c|c|c|c|c|c|c|c|c|}
\hline \multirow[t]{2}{*}{ Regions } & \multicolumn{4}{|c|}{ Under 5 infant mortality rate for 1,000} & \multicolumn{4}{|c|}{ Infant mortality rate for 1,000} \\
\hline & 1992 & 1998 & 2006 & Projection for $2010^{\star}$ & 1992 & 1998 & 2006 & $\begin{array}{l}\text { Projection } \\
\text { for } 2010\end{array}$ \\
\hline Agadez & 335,5 & 302,9 & 110,0 & 70,4 & 335,5 & 302,9 & 53,0 & 36,2 \\
\hline Diffa & 356,1 & 343,4 & 120,0 & 78,8 & 356,1 & 343,4 & 63,0 & 45,4 \\
\hline Dosso & 284,6 & 238,2 & 215,0 & 187,0 & 284,6 & 238,2 & 97,0 & 88,6 \\
\hline Maradi & 390,9 & 373,6 & 231,0 & 181,8 & 390,9 & 373,6 & 106,0 & 89,6 \\
\hline Tahoua & 335,5 & 302,9 & 214,0 & 172,2 & 335,5 & 302,9 & 91,0 & 74,6 \\
\hline Tillabery & 283,1 & 246,7 & 193,0 & 159,6 & 283,1 & 246,7 & 74,0 & 58,0 \\
\hline Zinder & 356,1 & 343,4 & 269,0 & 235,1 & 356,1 & 343,4 & 113,0 & 102,2 \\
\hline Niamey & 156,6 & 147,3 & 132,0 & 121,2 & 156,6 & 147,3 & 57,0 & 54,4 \\
\hline Niger & 318,12 & 273,8 & 198,0 & 156,8 & 318,2 & 273,8 & 81,0 & 67,1 \\
\hline
\end{tabular}

Table 2: Mortality rate of infant and child's death out of 1000 in the other regions.

This is symptomatic of the health pre transitional phase in which the land is located. The table below shows the infant child and infant mortality rates in the different regions of Niger (Table 2). The table shows that improvements in child survival between birth and age 5 have been observed since 1990. In fact, the child mortality fell from
318.2 per 1000 births in the early 1992 to 198 per 1000 births in 2006 (EDSN-MICS 2006), a significant leap of over 120 points in fourteen years. It may be noted, however, that the decline in child mortality is observed between one and five years. Infant mortality and its neonatal and post-neonatal components did not change significantly between 
1992 and 1998, but experienced a significant decline from 2006. The stagnation of infant mortality is just like that of fertility, observed over the decade.

The analysis of changes occurring in child mortality by demographic characteristics, relationships between fertility in general, the fertility cycle in particular and child mortality in the country among the poorest groups compared to the richest ones will help understand the problem of infant mortality.

\section{Literature Review}

Amadou [4] conducted this analysis for two hospitals in Niamey. He examined the relationship between income inequality and health status after access to care. Based on an ordered multinomial probit model, he found that the predicted probability in obtaining better health is more important for higher income categories.

Jusot [5] investigated the relationship between mortality and income inequality in France. His findings reveal that the risk of death is highly correlated with income. This relationship can be found throughout the income distribution, regardless of the effect of socioprofessional categories. A multilevel analysis allowed him to show that the inequality of income in the dwelling areas is in itself a determinant of mortality, after checking on the regional characteristics, such as the provision of care and unemployment rate.

The work of Preston [6], resulting from international comparisons has led to the conclusion that life expectancy did not increase continuously with per capita income. While in developing countries the average wealth largely explains the average health status of populations, this relationship is shattered among the rich countries. Wilkinson [7] has put to the table the debate on the relationship between income and health inequalities, highlighting a -0.81 correlation between life expectancy of 11 industrialized countries and the Gini index of income. It was hypothesized that the inequalities resulted in Gini index of income was a key determinant of health. This proposal has provoked considerable interest, even though the methodological approach based on international comparisons was questioned. The limits of this reflection from the fact that this type of study does not correspond in any way to a monitored experiment, as the health policies implemented and the sociocultural context differ greatly from one country to the other. To overcome these methodological problems, several studies have tested the correlation between inequality and health on American data. Kaplan et al. [8] and Kawachi and Kennedy [9] found a positive relationship between the level of inequality in every US state and several health indicator ${ }^{2}$. This relationship also appears robust to the choice of inequality indicator. It is also confirmed in France, where the life expectancy of each region decreases with the level of intra-regional inequalities [10,11]. In reality, several hypotheses on the determinants of individual health may involve a correlation between population health and inequalities $[12,13]$.

The first assumption now known as statistical artifact term is the existence of a concave relationship between income and health. If health is an increasing function of income but diminishing returns, any increase in income inequality will result in a decrease in the average health status of the population, since the improvement of the health status of a rich person benefiting from a transfer of income will be less than the deterioration of health by the loss of income from a poor person [14]. Many works, carried out exclusively on US data, and thus in a framework for access to very specific care, have shown the existence of the concave relationship between income and health $[15,16]$. According to the second assumption made by Wilkinson [2] and Kawachi [3], income inequality has a direct effect on individual health. This negative externality would be induced by a lower level of social capital and reduced social cohesion or by an effect of social comparisons on health $[3,17]$. Capital of the indicators used by Putnam [18] is good predictors of differences in life expectancy between American. Social capital indicators used by Putnam [18] are good elements to illustrate the differences in life expectancy intra American States [10]. Finally, this correlation may not reflect a direct effect of inequality, but rather the impact of geographical features, which are themselves correlated with inequality, such as local political decisions [3,12]. Income differences induce conflicts of interest, which may result in particular less generous social policies. Thus, US states where income distribution is more unequal have both a higher mortality rate, higher unemployment rate, higher rate of crime and incarceration, a good number of uninsured for higher health care and a lower level of education $[8,19]$. However, according to Legrand [20], the correlation between life expectancy and income inequality is robust to the introduction of the share of health expenditure financed by the public sector among 32 industrialized countries.

\section{The Theoretical Foundations of Income Inequality Indices}

The proposed measures of inequality are numerous. They can be grouped by type, according to the different paradigms on which they are based. It is also important to emphasize that these different types of indexes measure different aspects of the issue of inequality. We will present in this analysis, some measures that represent a wide range of quantitative treatment of inequality and contains the most commonly used indicators in literature and practical life. The indexes below are expressed in a finite population $\mathrm{U}$ of size $\mathrm{N}$. Income observation I is defined by $y$. The distribution of income is assumed to be ordered, $\mathrm{i}$ thus represents the observation rank

Some measures that represent a wide range of quantitative treatment of inequality and contains the most commonly used indicators in the literature and in practice ${ }^{3}$. The indices below are expressed in a finite population $\mathrm{U}$ of size $\mathrm{N}$. Income observation $\mathrm{i}$ is defined by $y$. The distribution of income is assumed ordered; $i$ also represents the rank of the observation.

\section{The Gini Index}

Perhaps the most famous of inequality index and the most traded in the literature, the Gini index is one of Laeken indicators of inequality. It measures the extent to which the distribution of income individuals or households within a country deviates from a perfectly equal distribution. It is a number between 0 and 1 . It is zero if the distribution is absolutely equal and equal to the unity if the wealth is

2 Health indicators used are mortality rates for all causes of death, the infant mortality rate, the mortality rate from cancer, for heart disease, the homicide rate and disability.

3 The indicators are the number of associations and confidence indexes between citizens, such as the trust we have in others or the feeling that others are only interested in themselves. 
owned by a minority of people. It is so high that the distribution is unequal:

$$
\text { Gini }=\frac{2 \sum_{i=1}^{N} i y_{i}}{N \sum_{i=1}^{N} y_{i}}-\frac{1}{N}-1
$$

\section{The Atkinson Index}

The Atkinson indicator uses a standard, taking into account the inequalities. This standard allows the image of the Theil index, to give more or less importance to inequalities depending on whether one is on top or bottom of the income distribution. This indicator represents the loss of income that people would accept for income distribution to be equal: $\mathrm{X} \%$ indicator shows that the willingness of people to give $\mathrm{x} \%$ of their resources in exchange of an equal distribution. It takes the general form:

$$
\begin{aligned}
& A_{\alpha}=1-\left[\frac{1}{N} \sum_{i=1}^{N}\left(\frac{y_{i}}{\bar{Y}}\right)^{1-\alpha}\right]^{\frac{1}{1-\alpha}} \text {, si } \alpha \neq 1 \text { et } A_{\alpha}=1 \\
& -\prod_{i=1}^{N}\left(\frac{y_{i}}{\bar{Y}}\right)^{\frac{1}{N}}, \text { si } \alpha=1
\end{aligned}
$$

Using the generalized average we have:

$$
\begin{aligned}
& M^{\alpha}=\alpha \sqrt{\frac{1}{N}} \sum_{i=1}^{N} y_{i}^{\alpha} \text {, si } \alpha \neq 0 \text { et } M^{\alpha}=\left(\prod_{i=1}^{N} y_{i}\right)^{\frac{1}{N}} \text {, si } \alpha \\
& =0 \text {. on } a: A_{\alpha}=\frac{M^{1}-M^{1-\alpha}}{M^{1}}=1-\frac{M^{1-\alpha}}{M^{1}}
\end{aligned}
$$

The Atkinson index is therefore a function of the parameter. For this study, we used the two index values for the parameter.

\section{The Theil Index}

The Theil index (1967) $G E_{\alpha}$ is calculated by the following equation:

$$
G E(\alpha)=\frac{1}{\alpha(\alpha-1)}\left[\frac{1}{N} \sum_{i=1}^{N}\left(\frac{y_{i}}{\bar{y}}\right)^{\alpha}-1\right]
$$

$\mathrm{N}$ represents the size of the population, the income of individual i, $\bar{y}$ the average income. The parameter $\alpha$, represents the distances weight between incomes at different points of the distribution. The Theil index is based on the entropy measure, that is to say, the difference between a uniform and equal distribution observed distribution. The more a suite is disordered, the more entropy is large. Here, the more revenues are scattered, the more the Theil index is high. This index has the advantage to be broken; it can be added for different subgroups.

\section{Methodology}

In this work, the logit model is used to explain infant mortality in Niger. With this model, we assume that the unobservable individual health capital $H_{\mathrm{i}}$ is explained by observable characteristics $X_{\mathrm{i}}$ and a residue.

$\mu_{\mathrm{i}}$ distributed according to a logistic law.

$$
H_{\mathrm{i}}=\alpha=X_{\mathrm{i}} \beta=\mu_{\mathrm{i}}
$$

Referring to health capital models, death occurs when the level of health capital falls below a minimum threshold Hmin is equal to 0 $[21,22]$. The death probability $P(D=1)$ is equal to:

$$
P(D=1)=P\left(H_{\mathrm{i}}<H_{\min }\right)=1-F\left(\alpha+X_{\mathrm{i}} \beta\right)
$$

With this model, the estimated value $\beta$ of the parameters depends only on the differences in distribution of characteristics $X$ in the population of the deceased and the survivors. The size of each subpopulation has no influence in determining these parameters.

When express the variable $X_{1}$ in dichotomous form, then the $\beta_{1}$ exponential is equal to the odds ratio associated with the variable, that is to say the ratio of odds ratios between $X_{1}=1$ individuals and $X_{1}=0$ characteristic features.

$$
\begin{array}{r}
X_{1}=0 \text { individuals characteristic feature } \\
\exp \beta_{1}=O R_{1}=\frac{\frac{P\left(D=1 / X_{1}=1\right)}{P\left(D=0 / X_{1}=1\right)}}{\frac{P\left(D=1 / X_{1}=0\right)}{P\left(D=0 / X_{1}=0\right)}}
\end{array}
$$

The estimation of the study model will be based on the database used (EDSN-1998 or EDSN-MICS 2006) and depending on the nature of the variable expressing the income of the head of the selected household ${ }^{4}$. This leads us to consider four models including:

- The 1.1 and 2.1 models; using the EDSN-1998 database (respectively EDSN-MICS 2006) with the variable measuring the income of the head of the household and wellbeing quintiles.

- The Models 1.2 and 2.2; using the EDSN-1998 database (respectively EDSN-MICS 2006) with the variable measuring income of the head of household and the welfare index.

Models 1.1 and 1.2 will allow capturing the direct effect of income inequality 6 (through welfare quintiles) the likelihood of death.

The 1.2 and 2.2 models will capture the direct effect of income inequality (income index) on the probability of death. This modeling will also analyze the influence of the level of inequality in each region in 1998 and 2006 evaluated from EDSN and EDSN-MICS surveys.

This hypothesis is related to the explanatory model of infant mortality in Niger, which assumes that the health status of an individual is determined in part by the characteristics of the environment in which he lives $[23,24]$. This analysis is conducted in taking into account the various criticisms in the literature for the selection of; which remain characteristics environmental variables one hand and the estimation methodology used on the other [3,25].

4 The income health relationship is actually dual, the problem of indignity is set in this situation because the children's populations provide an interesting analytical framework if the labor supply is zero and that the state of child Health has no impact on the parent labor supply decision. The use of the income of the spouse, can be used to demonstrate a direct effect on health resources, if one admits that the labor supply of one of the spouses is independent of the health status of the other. 
Page 5 of 7

In this situation, we consider that individuals from the same region may be subject to a specific risk of mortality, possibly explained by the characteristics of the region. That is to assume that the health of an individual belonging to region $j$ is explained at the individual level through its individual characteristics $X_{\mathrm{ij}}$ and individual residue $e_{\mathrm{ij}}$ supposed to be distributed according to a logistic law, and at the aggregate level by regional characteristics variables and a random effect region, which is normally assumed distributed:

$$
\left(\mu \rightarrow N\left(0, \sigma_{\mu}\right)\right): H=\alpha_{0}+C_{j \gamma}+\mu_{0 j}+X_{i j} \beta+e_{i j}(4)
$$

Individual residues are assumed to be independent of regional residues and residues of each type are assumed to be independent among themselves.

The introduction of regional random term does not change the estimated value of the explanatory variables and parameters, but corrects deviations of residual autocorrelation of residuals within each region and therefore the omission of other regional variables [26].

\section{Description of Data Sources}

\section{Dependent variable and main variables of interest}

In our study the child is the unit of analysis but we rely on individual women's questionnaire to collect information needed for this analysis. This brings us to collect economic information, demographic and professional mothers or spouses. Appendix 1 presents the essential variables used in this analysis. All these variables come from individual women's questionnaire. That of EDSN-1998 concerned 7577 eligible and surveyed women, and that of the EDSNMICS (2006) 9223.

\section{Dependent variable}

In this model, the dependent variable is represented by the occurrence of the death of a child under five in the surveyed household. It is a qualitative variable that takes the value 1 when a death has been reported in the household and 0 otherwise.

\section{The explanatory variables are represented}

- The level of welfare of households considered in two ways: First through five quintiles classes, welfare and then by the value of the index of well-being graduated from 0 to 4 .

- Occupational status of the household head.

- Region that accounts for eight regions of the country.

- Age of mother.

- Marital status of the household head, residence.

- Gender to discriminate men and women heads of household.

- Women's level of education.

\section{Sampling}

The sample target I'EDSN-II 1998 was 7,000 women of reproductive age (15-49 years) and 3500 men aged 15 to 59 years. However, with EDSN-MICS 2006, 8418 households were selected and among them, 7,824 households were identified. Of these, 7660 have been successfully surveyed, representing a $98 \%$ response rate. Nevertheless, despite these differences, the response rates are about the same for both surveys.

\section{Results}

Exploiting the basis of data from the 1998 and EDSN EDSN-MICS 2006 allowed the development of statistics below in health and income inequality at the national and regional level. The table below shows the income inequality indicators at national level (Table 3).

\begin{tabular}{|l|l|l|l|l|}
\hline & \multicolumn{2}{|l|}{1998} & 2006 \\
\hline & Multiplier & Gap-Type & Multiplier & Gap-Type \\
\hline Gini index & 0,2242 & 0,0041 & 0.517 & 0,2538 \\
\hline $\begin{array}{l}\text { Atkinson index } \\
(0.5)\end{array}$ & 0,0456 & 0,0015 & 0,1641 & 0,0041 \\
\hline Theil index & 0,088 & 0,0032 & 0,2963 & 0,0073 \\
\hline
\end{tabular}

Source: Author's calculation-data: EDS-1998 EDSN-MICS 2006.

Table 3: Evolution of income inequality indicator at the national level.

The results of the Gini index shows that inequality has increased in general from 0.224 in 1998 to 0.517 in 2006 . This can be confirmed by that of the Atkinson index from 1998 to 2006. The results the Theil index between 1998 and 2006 also confirm the increase in inequality. Indeed this index increased from 0.088 in 1998 to 0.2963 in 2006.

Appendix 2 shows the distribution of the three income inequality indexes by region. Gini index shows that in 1998, Tahoua/Agadez and Zinder/Diffa regions have the highest income inequality indexes with respectively 0.24 and 0.22 . Yet, Tillabery and Dosso regions have the lowest inequality indexes, respectively 0.2037 and 0.17 . EDSN-MICS 2006 indexes show that Agadez and Dosso having the most unequal indexes compared to those of Tahoua and Maradi have the lowest indexes. Overall, the Atkinson indexes between these two periods confirm these results.

\section{Results of Econometric Models}

In model 1.1 and model 1.2 , the welfare variable is taken into account through the five quintiles representing the income level of the household head. In model 2.1 and model 2.2, well-being is taken into account through an ordinal variable called index of well-being. Because of the strong correlation between employment status and quintiles in EDSN-1998 survey, we preferred to estimate this equation by alternately using the quintile variables and socio-professional status. Despite this, the analysis of the results of model 1.1 (A), (Annex 3) clearly shows that the explanation of child mortality across quintiles leads to significantly interesting results. Indeed, these results verify that when moving from a lower class to upper class income, child mortality decreases. The value of the odds ratio 1.1 model (A) confirms these results.

Indeed, the value of the odds ratios associated with income quintiles also allows to better perceive the extent of social inequalities in the realm of health in Niger because the risk of death of the fourth quintile is about 2.18 times lower than the risk of death for the first quintile. Regarding the variable region; the risk of death in the most egalitarian regions (Dosso, Tillabery) is significantly lower than the risk of death from other regions (Maradi, Tahoua/Agadez, Zinder/Diffa). These findings are confirmed by those of the odds ratio in the Maradi region and that of Diffa/Zinder, far beyond the probabilities of death observed in other regions of the country. 
Page 6 of 7

Among the variables of interest was the woman's age, level of education of women, place of residence and marital status. Overall, these variables of interest have also significantly contributed to the explanation of the mortality in this model 1.1.

The level of education variable indicates that the higher the level of women's education increases the higher the probability of death decreases. This is reflected in the results of the odds ratio that show that the probability of death when the woman is uneducated is 2.41 times higher than when she has a secondary school education level. Residential environment is negatively correlated with child mortality. It appears that this mortality is lower in urban than in rural areas.

The estimated model 2 (A), in Appendix 4 (EDSN-MICS 2006) confirmed some results of model 1.1 (A) obtained with some key explanatory variables (level of well-being, social and professional status, region) and some variables of interest (age group, education level, marital status).

Estimation of the model 1.2 (B) shows that certain terms of the socio-professional status variable proved statistically significant. Thus, the probability of death in an employee household is lower than that found in a farmer's household. These very favorable results noticed with civil servants can be explained in terms of reduction of child mortality due to accessibility to health care of the household and the income stability of the head of household, social security or health insurance for some.

The results of the categories of the women's education variable are consistent and reinforce those found with model 1.1. Indeed, these results allow us to conclude that a fight in reducing the rate of child mortality through consistent action in improving the education of women. These results illustrate the effort between the period 1998 and 2006 regarding the investigation that the relationship between education and child mortality has gone from a positive correlation (EDSN-1998) to a negative one. This encourages the government education policy. In fact, between the two periods, the number of uneducated women decreased (from $80 \%$ to $77 \%$ ) and women with primary education (respectively secondary and higher) increased.

Appendix 5 presents the results of estimated model 2.1 with the database EDSN-1998. The peculiarity of model 2.1 is the replacement of five welfare quintiles by a single index measuring the level of wellbeing.

For the results of this model, it is noted that this variable is positively correlated with child mortality. This result is not consistent with the hypothesis that supports a reduction of this mortality with increasing income. This allows us to globally justify the reduction in the rate of child mortality observed in Niger between 1998 and the EDSN-EDSN-MICS 2006 is not really due to a substantial improvement of the income or household welfare but this is rather the result of several causes (improving and increasing the supply of rural health care, increase the level of education of women and success of the awareness campaigns and taking care of certain diseases) which act on reducing mortality.

However, the results of the terms of the socio-professional status variable (Civil servants, traders, farmers, manual workers and other independent) and region (Agadez/Tahoua, Diffa/Zinder, Dosso, Maradi, Tillabery, Niamey) are identical to those of the model 1.1. The results of the terms of auxiliary variables age, education and place of residence do not show major differences from those of model 1.1.
Appendix 5 presents the results of estimate the model 2.2 with the EDSN-MICS database 2006. The analysis of the results of model 2.2 with database EDSN-MICS 2006 confirms many previously known results.

The results of the different regions of the country are also identical to those of model 1.1 this time with Zinder and Maradi leading with higher child mortality marginal coefficients, respectively (1.143 and 1.013) compared to other regions of countries. This reflects the reality that eight-year period, socio geographic disparity in child mortality in Niger remains an obvious reality as confirmed by the probability of death through the odds ratio of Zinder and Maradi.

\section{Conclusion}

The analysis of income inequality indicators showed that income inequality has increased in Niger both at the national and regional levels, going through the 1998 DHS at the EDSN-MICS 2006.

The econometric analysis of the results of the relationship between child mortality and income inequality in Niger was used to assess these results in terms of static situation (The two years of the EDSN investigation in Niger) and in the context of a dynamic situation by comparing the results of the EDSN-1998 to those of EDSN-MICS 2006.

Moving from EDSN-1998 at the EDSN-MICS 2006, probably there was a remarkable decrease in child mortality in Niger. However, given the results mentioned above, we can say that this decline in infato juvenile mortality is primarily related to the impact of other factors that have most effect in the decrease than the improvement of the income of the mainstream population.

The same analysis with the socio-professional status variable allows us to conclude that in 1998, the terms of such variables had no significant impact in reducing child mortality. However, in 2006, the same terms significantly explained the decline in mortality especially for this category of employees.

As far as the variable of a specific region of the country, it appeared that from the EDSN-1998 at the EDSN-MICS 2006; a positive correlation between this mortality and different regions of the country with the regions leading.

The results of paramount importance clearly indicate that to reduce this mortality:

- The government of Niger must succeed in reducing the social inequality in terms of income.

- The government should also make courageous decisions in favor of certain socio-professional classes that experience much serious mortality rate compared to other classes.

- It must take specific and sustained policies in areas with the highest mortality rates over decades.

\section{References}

1. National Statistics Institute (NSI) (2008) Trends, profile and determinants of poverty in Niger: 2005-2008.

2. Wilkinson R (1996) Unhealthy Societies: the Afflictions of Inequality. Routledge, London.

3. Kawachi I (2000) Income Inequality and Health, in Social Epidemiology. Oxford University Press. 
Citation: Ousmane A (2017) Infant Mortality Juvenile and Inequality Income in Niger: Evidence for Regional Differences through Two Case Studies. J Glob Econ 5: 263. doi:10.4172/2375-4389.1000263

Page 7 of 7

4. Amadou O (2006) Unique Thesis : "Economic Analysis of the organization and funding of hospital care in Niger. University of Ouagadougou.

5. Jusot F (2004) Mortality and income inequality in France. Working paper No. 32, DELTA, CNRS, ENS. Paris .

6. Preston SH (1975) The changing relation between mortality and level of economic development. A Journal of Demography 29: 231-248.

7. Wilkinson RG (1992) Income distribution and life expectancy. British Medical Journal 304: 165-168.

8. Kaplan GA, Pamuk ER, Lynch JW, Cohen RD, Balfour JL (1996) Inequality in income and mortality in the United States : analysis of mortality and potential pathways. British Medical Journal 312: 999-1003.

9. Kawachi I, Kennedy BP (1997) The Relationship of Income Inequality to Mortality: Does the Choice of Indicator Matter. Social Science and Medicine 45: 1121-1127.

10. Kawachi I, Kennedy BP, Lochner K, Prothrow-Stith D (1997) Socia Capital, Income Inequality, and Mortality. American Journal of Public Health 87: 1491-1498.

11. Jusot F (2003) Revenue and mortality: Economic analysis of social inequalities in health in France. PhD thesis at the EHESS.

12. Deaton A (2001) Health, Inequality and Economic Development. NBER WP 8318

13. Wagstaff A, van Doorslaer E (2000) Income Inequality and Health: What Does the Literature Tell Us

14. Gravelle H (1998) How much of the relation between population mortality and unequal distribution of income is a statistical artifact. British Medical Journal 316: 382-385.
15. Mellor JM, Milyo J (1998) Income Inequality and Health Status in the United States: Evidence from the Current Population Survey. The Journal of Human Research 37: 510-539.

16. Smith JP, Kington R (1997) Demographic and Economic Correlates of Health in Old age. Demography 34: 159-170.

17. Wilkinson RG (1997) Comment: Income, Inequality and Social Cohesion. American Journal of Public Health 87: 1504-1506.

18. Putnam RD (1995) Bowling alone: America's declining social capital. Journal of Democracy 6: 65-78.

19. Kawachi I, Kennedy BP, Wilkinson RG (1999) Crime: social disorganization and relative deprivation. Social Science and Medicine 48 : 719-731.

20. Legrand JL (1987) Inequalities in Health. Some International Comparisons. European Economic Review 310: 182-191.

21. Grossman M (1972) On The Concept of Health Capital and The Demand for Health. Journal of Political Economy 80: 223-255.

22. Erlich I, Chuma H (1990) A model of the demand for longevity and the value of the life extension. Journal of Political Economy 98: 761-782.

23. Macintyre S, Ellaway A (2000), "Ecological Approaches : Rediscovering the Role of the Physical and Social Environment", in Social Epidemiology.

24. Kawachi I, Berkman LF (2003) Neighborhoods and health. Oxford University Press.

25. Subramanian SV, Blakely, Kawachi I (2003) Income Inequality as a Public Health Concern: Where do we stand? Health Services Research 38: 153-167.

26. Diez-Roux AV (2000) Multilevel Analysis in Public Health Research. Annual Review of Public Health 21: 171-192. 